\title{
A CONSTITUCIONALIZAÇÃO DO DIREITO DO TRABALHO NA TRILHA DO PRINCÍPIO DA DIGNIDADE DA PESSOA HUMANA
}

\author{
Rodrigo Coimbra ${ }^{1}$ \\ Ellara \\ Valentini \\ Wittckind ${ }^{2}$
}

\begin{abstract}
Resumo
O presente artigo trata da constitucionalização do Direito do Trabalho no Brasil, para que se compreendam as razões e os caminhos seguidos por este ramo do Direito, partindo da codificação do Direito Civil, passando pelas origens do Direito do Trabalho até sua constitucionalização, bem como dos desafios que essa trilha gera para avanços das relações trabalhistas. Assim, tem-se que o movimento de constitucionalização do Direito do Trabalho consagra os princípios e valores do ordenamento jurídico, em especial o da dignidade da pessoa humana, pois se preocupa com a valorização da pessoa do trabalhador, o qual deve ser protegido contra arbitrariedades do Estado e do empregador, de condições prejudiciais à sua saúde e segurança, entre outros aspectos ainda presentes no contexto da sociedade globalizada e multicultural. Para isso, através do método sistemático e da abordagem qualitativa, propõe-se investigar se o Direito do Trabalho, após sua constitucionalização, tem possibilitado a superação de conflitos intersubjetivos decorrentes do não reconhecimento de dignidade do trabalhador, como ser humano detentor de direitos sociais.
\end{abstract}

Palavras-chave: codificação - Direito Civil - constitucionalização - Direito do Trabalho dignidade

\section{INTRODUÇÃO}

O presente artigo trata do tema da constitucionalização do Direito do Trabalho, no caminho da constitucionalização do Direito Privado, quando os direitos - dentre os quais os trabalhistas - passaram a serem norteados pelos valores e princípios da Constituição Federal de 1988.

A pesquisa se justifica porque esse resgate possibilita que se compreendam as razões e os caminhos seguidos pelo Direito do Trabalho no Brasil no contexto da

\footnotetext{
${ }^{1}$ Doutor em Direito pela Pontifícia Universidade Católica do Rio Grande do Sul - PUCRS. Professor da Universidade Federal do Rio Grande do Sul - UFRGS e da Universidade do Vale do Rio dos Sinos UNISINOS. E-mail: rodrigo.coimbra@terra.com.br.
} 
constitucionalização do Direito Privado e todo o manancial proporcionado a esse ramo do Direito desde suas origens até sua constitucionalização, bem como dos desafios que essa trilha gera para avanços das relações trabalhistas.

Propõe-se investigar se o Direito do Trabalho tem possibilitado a superação de conflitos intersubjetivos decorrentes do não reconhecimento de dignidade do trabalhador, como ser humano detentor de direitos sociais.

Para tanto, o presente trabalho está dividido, no seu desenvolvimento, em três sessões. Inicia-se analisando o processo de codificação do Direito Privado, passando pelas origens do processo codificatório até seu desgaste especialmente em razão do fato de que a sociedade industrial ou pós-industrial reclamava por direitos sociais, repelindo o individualismo marcado no Direito Civil codificado e pelo Estado Liberal.

Na segunda parte, aborda-se o nascedouro do Direito do Trabalho a partir dos conflitos coletivos (semente do Direito Coletivo do Trabalho) e não como apêndice do Direito Civil, visando que se possa compreender suas origens, razões, adaptação ao processo constitucionalização do direito privado, reconhecimento e todo o caminho que se abriu a partir de então para constantes debates e avanços desse ramo do Direito tão dinâmico e que influi diretamente na vida dos trabalhadores, empregadores, Estado e sociedade.

$\mathrm{Na}$ terceira sessão, o objeto será o princípio da dignidade da pessoa humana (do trabalhador) - analisada sobretudo a partir do referencial teórico de Kant, Hegel e Sarlet -, destacando a importância do princípio maior do Direito Constitucional contemporâneo para a valorização das relações de trabalho e do Direito do Trabalho.

Como método científico de abordagem do assunto será utilizado o método sistemático. A abordagem da pesquisa se dará pelo modelo qualitativo na medida em que se buscará o entendimento do fenômeno em seu próprio contexto. Em função das peculiaridades da pesquisa qualitativa a mesma tende a ser menos estruturada, de modo a trabalhar com o que é importante para os indivíduos, sistemas sociais, políticos, jurídicos e econômicos, utilizando-se para tanto, da investigação profunda sobre o tema proposto na presente pesquisa. Desta forma a mesma parte de questões ou focos de interesse amplos, que vão se definindo à medida que o estudo se desenvolve.

\section{BREVE HISTÓRICO DO FENÔMENO DA CODIFICAÇÃO DO DIREITO PRIVADO}

\footnotetext{
${ }^{2}$ Mestranda em Direito Público, Linha de Pesquisa Novos Direitos, Sociedade e Transnacionalização Universidade do Vale do Rio dos Sinos - UNISINOS. E-mail: ellarav@ hotmail.com. vol.09, nº. 03, Rio de Janeiro, 2016. pp. 
O movimento da codificação foi conhecido desde a Antiguidade, embora os primeiros códigos não tenham sido esquematizados, como o foram posteriormente, pois abarcavam tanto regras de ordem civil, como penal, comercial e outras. Foi o caso do Código de Hamurabi, de 2.000 a.C., o qual objetivava separar o ordenamento jurídico de questões morais e religiosas. Outros exemplos de códigos antigos são: a Legislação Mosaica (de Moisés), do século XII a.C., reunida posteriormente na Bíblia, sob os títulos de Gênesis, Êxodo, Levítico, Números e Deuteronômio; a Lei das XII Tábuas, datada do século V a.C., a qual resultou da luta dos plebeus por direitos iguais aos das classes mais abonadas; o Código de Manu (compilado na Índia, entre os séculos II a.C e II d.C.); o Alcorão, originado no século VII, o qual foi e é interpretado de forma diferente conforme a realidade dos povos muçulmanos, ao longo do tempo e as tradições de cada país nos quais vivem.

Entre os séculos XVII e XVIII deu-se a Era das Codificações, em decorrência da teoria da divisão dos poderes de Montesquieu, quando ao legislativo coube a criação do direito, através do pensamento racionalista, considerando a ideia de que a natureza humana determinava a razão e esta, o direito. Ademais, neste momento, havia necessidade de ser resguardada a unidade do direito, para que questões de ordem social e moral fossem também unas. Foi a partir deste momento que despontou e se desenvolveu a regulação das relações privadas através do direito criado pelo Estado. (NADER, 2007)

O Direito Civil atual teve origem no Direito Romano, o qual se processou entre duas codificações: a Lei das XII Tábuas e o Corpus Juris de Justiniano, sendo que seu cerne mantém-se vivo até os dias atuais. Na linha do que leciona Venosa (2007), o Direito Romano deve ser considerado um divisor de águas na Ciência do Direito, haja vista que alterou aquilo que se tinha por justiça e por direito.

Importante que se ressalte que a codificação do Direito Romano ocorreu ainda durante a República, quando foram aglutinadas as regras decorrentes de costumes e tradições, que se criaram ao longo do tempo. Disso, surgiu o Corpus Juris Civilis (565 d. C.), o qual foi dividido em: Código, com 12 livros, nos quais foi tradado acerca das fontes do direito, do processo, do direito privado e penal, entre outros; Digesto, no qual foi compilada jurisprudência; Institutas, uma espécie de doutrina, e as Novelas, nas quais continham reformas legislativas. (NADER, 2007)

A obra do Direito Romano é muito importante porque foi transmitida ao longo do tempo para os povos conquistados pelo Império Romano, disseminando-se por toda Europa e, posteriormente, para a Ásia e a África, com a fase das colonizações. O Brasil, em função da colonização portuguesa, recebeu a herança romana através das Ordenações Afonsinas, vol.09, nº. 03, Rio de Janeiro, 2016. pp. 
Manuelinas e Filipinas. (NADER, 2007)

A partir de 1804, com o Código Napoleônico, os direitos decorrentes da liberdade individual e da propriedade foram assegurados formalmente, após séculos de opressão das classes menos favorecidas financeiramente. Entendia-se que a codificação representava certeza e segurança jurídicas, pois o sistema do Direito Privado estaria agrupado num só documento, fechado, do qual todos os cidadãos poderiam socorrer-se. (NADER, 2007)

Assim, o Código Napoleônico possuía certas características importantes que o qualificaram como o primeiro Código da era moderna, sendo, em suma: a) culto ao texto da lei, pois esta era a fonte do Direito, por excelência, e dentro dos limites dela este deveria ser aplicado; b) a vontade do legislador era fato indispensável de ser analisado para se estabelecer a resposta à lide, em caso de ausência de lei; c) forte atuação do Poder Legislativo, ao qual cabia construir o Direito, ou seja, ao Judiciário cabia meramente a aplicação da lei ao caso concreto (juiz "boca da lei”), sem qualquer ingerência jurisprudencial ou construção de respostas alternativas, e estagnação do estudo do Direito, pois a doutrina praticamente não tinha com o que se ocupar, diante da literalidade da lei.

Em 1896, na Alemanha, foi publicado o Código Civil Alemão, o BGB, marcando o início da preocupação da legislação codificada com a história, a tradição e os costumes dos povos (CANARIS, 2002, p. XCIV).

Com base no Jusracionalismo e no Iluminismo, as codificações europeias foram marcadas pelo ideal da sociedade organizada através da soma de vontades em uma só (contrato social), do compromisso com a garantia da liberdade e dos valores do Direito Natural. De acordo com Wieacker (WIEAKER, 1967, p. 240):

[...] o jusracionalismo europeu constituiu, na verdade, uma revolução cultural, mas traçada passo a passo por uma tradição coesa que, através das teorias sociais da Idade Média, remonta à filosofia greco-helenístico-romana. A unidade desta tradição é garantida não apenas pela continuidade histórica, mas também pela unidade dos problemas; já a execução deste projecto se processou por formas muitíssimo diversas.

Neste momento, havia um "fetichismo do Código Civil para as relações de direito privado", e uma certa indiferença pelo direito constitucional. Num contexto em que os direitos ligados à liberdade e à propriedade privada se sobressaíam a qualquer outro direito, e que o Estado não intervinha nas relações privadas, não poderia se esperar que fosse diferente o anseio social: de garantia dos direitos privados. As leis esparsas eram raras, além do que, haviam sido criadas para sanar lacunas no Código (TEPEDINO, 2008, p. 3).

Essa lógica de sistema determinou que as disposições dos Códigos fossem concatenadas, no intuito de que se pudesse tratar os iguais de modo igual e os diferentes de 
modo diferente, conforme a desigualdade. Esse direito codificado era previsível, ou melhor, a solução dada ao litígio, pelo direito, deveria ser previsível, faltando a este Direito uma ordem externa, uma comunicação com outros sistemas, para que se representasse, efetivamente, o fenômeno cultural, social e histórico que deveria ser. (TIMM, 2008)

A lei era a base do Direito, devidamente sistematizada, a fim de que pudesse ser interpretada por si mesma. (WIEAKER, 1967, s/p) A codificação, portanto, representava uma "estruturação juscientífica de certas fontes", que se dá sistemática e lentamente, através da influência da cultura, da tradição, dos anseios sociais, da economia, da política, etc.. (CANARIS, 2002, p. LXXXV)

O grande prestígio do Código Civil o elevou a norma máxima do Direito Privado, vindo a Constituição a servir como elemento subsidiário de integração, a ser utilizado pelo intérprete somente depois de ter recorrido à analogia e aos costumes, sem obter resposta. No Brasil, o Código Civil de 1916 detinha estas particularidades, ou seja, tinha o ideal de ser completo, sistematizado e regulador de todas as variantes de litígios da vida privada, com o apoio de normas regulamentadoras, sendo "uma mistura de influências da doutrina jurídica nacional do século, fundamentalmente de Teixeira de Freitas, com a codificação francesa e a ciência pandectista alemã”. (TIMM, 2008, p. 11)

Não obstante, entende Timm (2008, p. 5) que:

[...] quando se fala em codificação, não são dessas compilações de leis que se está a referir. Mas, sim, daquele fenômeno surgido em fins do século XVIII, originado da Escola Racionalista do Direito Natural e do Iluminismo, na França, e da pandectística, na Alemanha, já no século XIX.

Assim, defende o autor (TIMM, 2008, p. 4) que a codificação não deve ser vista como sistematização pura e simples do direito em seu tempo, porque a mesma preocupa-se com "novas formulações legais, mais genéricas e abstratas, buscando sempre maior clareza e precisão na enunciação dos preceitos, sistematizados sob o dogma da unidade e da completude do código".

Nesse linda, Timm (2008, p. 5) entende que a codificação clássica se caracteriza por:

- simplificação do sistema jurídico, com a nova concepção de formulação legislativa - genérica, abstrata —, diminui-se o número de disposições legais, que, além da redução, ficam também mais claras e precisas; além da própria redução do fenômeno jurídico, que fica restrito à lei, e, mais precisamente, ao Código; sempre na busca de segurança jurídica;

- racionalização do sistema jurídico, o sistema jurídico é visto como ordenação lógica dos preceitos enunciados nos códigos que se ligam entre si por derivações provenientes da mesma lógica;

- tendência à exaustividade na regulação de um âmbito ou setor jurídico, todos os conflitos sociais devem achar resposta no código, que regula exaustivamente a matéria que tem como objeto, sem qualquer lacuna; tem eficácia onicomprensiva. 
Modernamente, fala-se em direito codificado não somente formado por normas, como por valores e "princípios jurídicos, produto da relação dialética entre a intenção sistemática, exigida pelo postulado da ordem, e a experiência problemática, imposta pela realidade social”. Assim, "o sistema passa a configurar-se assim como uma ordem axiológica ou teleológica de princípios gerais, uma entidade aberta e dinâmica que continuamente se enriquece e constitui". (AMARAL, 1994, p. 49)

A codificação, portanto, alcançou lastro por todo mundo, fortemente marcada, como referido, pelo Code Civil Napoleônico (1804), e pelo BGB alemão (1896).

Porém, depois da década de 1930, no Brasil, e no início do século XX, na Europa, o "fetichismo" do Código Civil cedeu espaço aos reclames da sociedade, pelos direitos sociais, dentre os quais se destaca o Direito do(ao) Trabalho, vindo o Direito a necessitar de novas fontes, para poder garanti-los e assegura-los. (TIMM, 2008)

Assim, o desgaste do Código Civil apareceria, especialmente, em razão do fato de que a sociedade industrial ou pós-industrial reclamava por um direito social, ou seja, repelia o individualismo marcado no Direito Civil codificado e pelo Estado Liberal. Aos poucos, as Constituições passaram a tratar dos temas anteriormente eminentemente civis, como a função social da propriedade, os limites da atividade econômica, a organização da família. O Direito Civil, através das leis não codificadas, passou a preocupar-se mais com as relações privadas e os riscos delas decorrentes, e menos com o indivíduo em si. (TEPEDINO, 2008)

Nesse momento, o Estado Social não atuaria somente de maneira "reconhecedora e repressora", mas assistencialista e protetora de direitos. Tanto que os paradigmas do Estado Social foram a Revolução Industrial, a Primeira e a Segunda Guerras Mundiais, a crise econômica de 1929. A partir desses acontecimentos, somados a séculos de anseios sociais reprimidos, o Estado passou a atuar legislativamente no sentido de proteger os direitos fundamentais das pessoas, para que pudessem sustentar-se e a sua família, gozarem de bemestar, serem assistidos, quando necessário, etc.. (STRECK; MORAES, 2006, p.70-71) Foi quando a descodificação iniciou e, pouco a pouco, determinou uma mudança radical no Direito, vindo o Código Civil a ceder espaço para sistemas jurídicos diversos, no intuito de salvaguardar respostas para problemas sociais antes não alcançados pelo Direito Privado, nos quais se encaixam os direitos trabalhistas.
A DESCODIFICAÇÃO
DO DIREITO
PRIVADO,
A
CONSTITUCIONALIZAÇÃo DO DiREITO PRIVAdo E A EVOLUÇÃo
DO DIREITO DO TRABALHO: DO NASCEDOURO À 


\section{CONSTITUCIONALIZAÇÃO}

\section{A descodificação do direito privado}

Em termos históricos, Natalino Irti, em 1978, foi o primeiro autor a tratar a respeito da decodificazione, através do artigo L'età dela decodificazione, no qual demonstrou que o Estado Social transformou a legislação da Europa, fazendo com que a legislação da Itália, objeto do estudo do ensaio do autor, se voltasse aos princípios e valores da sua Constituição, para a resolução dos problemas da vida privada das pessoas, retirando do centro legislativo o Código Civil.

Destaca $\operatorname{Irti}^{3}$ (1999) que a noção de direito subjetivo, que passa a ser, na época do modelo de Estado Liberal, uma das mais altas expressões da autonomia dos sujeitos, com um casamento perfeito com o individualismo, é uma fundamental categoria jurídica para a construção e a sedimentação tanto do direito privado como do direito processual, com raízes importantes na Idade Média.

A "era da descodificação" se caracteriza pela "perda da característica de centralidade no sistema de fontes pelo Código Civil. A Constituição é a salvaguarda do indivíduo. As leis especiais têm seus próprios princípios gerais” (TIMM, 2008), vários institutos e situações não são regulados pelo Código Civil, além do que há cada vez mais situações novas que carecem de guarida e, em razão da habitual demora e/ou inação do Legislativo não podem ser olvidadas.

Além disso, a industrialização, retomada em grandes proporções após a Primeira Guerra, exigiu novas regulações a respeito de acidentes do trabalho e das próprias relações de trabalho. A maquinização, a mecanização, o operariado exigiram que novas leis fossem publicadas, à margem do Código. Nesse cenário, a liberdade contratual, a autonomia privada, a responsabilidade subjetiva e outros institutos tiveram de ser revistos, em benefício dos direitos dos trabalhadores. (TIMM, 2008)

A partir da descodificação do Direito Privado, o legislador passou a valer-se de regras gerais (RENÉ, 1998, p. 104-5), utilizando-se da interpretação para adequá-las ao caso concreto, às mais diversas situações apresentadas no âmbito social. Da mesma forma, mudou a linguagem da legislação, deixando um pouco de ser jurídica, passando a ser mais setorial. Ainda, o legislador passou a não somente impor comportamentos, aplicar sanções, mas também a incentivar, a fim de atingir os objetivos sociais. Exemplos disso são as isenções, os

\footnotetext{
${ }^{3}$ Conforme o autor, nessa época, “o valor originário e fundamental é constituído pelo indivíduo, por sua capacidade individual, por sua liberdade de escolher suas próprias metas, seus objetivos, assumindo sozinho o risco do sucesso e do fracasso". (IRTI, Natalino. L'età della decodificazioni. 4.ed. Milano: Giuffrè, 1999, p. vol.09, nº. 03, Rio de Janeiro, 2016. pp. 1651
} 
financiamentos subsidiados, as ações afirmativas, entre outros. Outrossim, a lei não se prestava somente para dirigir relações privadas, mas para estabelecer igualdade entre desiguais, zelar pela dignidade humana e pelos direitos da personalidade. Por fim, a nova forma de legislar ficou marcada pela normatização para determinados grupos, através da participação de sindicatos, associações, o que se verifica nitidamente no âmbito no Direito do Trabalho. (TEPEDINO, 2008, p. 3-21)

Com a limitação da autonomia da vontade em prol do interesse coletivo, o Estado consagrou valores solidarísticos, embora isto não tenha bastado para firmar a Constituição no centro do Direito Privado, porque ela era vista apenas como uma Carta Política, não dotada de eficácia jurídica imediata. (SARMENTO, 2006, p. 49)

No Brasil, pode-se dizer que o processo descodificatório iniciou com a Constituição de 1934, que em seu artigo 113, item 17, dispôs que o direito à propriedade não poderia ser exercido em desconformidade com o interesse social e coletivo. Ou, com a Constituição Republicana de 1988, que estabeleceu direitos sociais, e através de suas diversas normas, para outros diversos ramos do Direito, superou o conceito de mera Carta Política.

\section{A constitucionalização do direito privado}

Como consequência da descodificação, institutos anteriormente de alçada do Código Civil se tornaram parte do processo de constitucionalização do Direito Privado, ou seja, começam a ser tratados pelo Direito Constitucional, a fazer parte do texto da Constituição, através de normas programáticas, ou mesmo de eficácia imediata, especialmente no que tange aos direitos fundamentais e aos direitos sociais. (TIMM, 2008)

O Direito Individual do Trabalho enquadra-se na classificação de Direito Privado. Cabem aqui algumas digressões sobre a natureza jurídica do Direito do Trabalho, pois se trata de tema basilar, complexo e que ainda atualmente é controverso no âmbito doutrinário. ${ }^{4}$

O Direito Individual do Trabalho possui normas de ordem pública e normas de caráter dispositivo. Um exemplo é o art. 444, da CLT, que dispõe que as relações contratuais de trabalho podem ser objeto de livre estipulação das partes interessadas, em tudo quanto não contrarie as disposições de proteção ao trabalho, os contratos coletivos que lhes são aplicáveis e as decisões das autoridades competentes. (COIMBRA; ARAÚJO, 2014)

21).

${ }^{4}$ Para um estudo detalhado sobre as teorias sobre a natureza jurídica do Direito do Trabalho ver COIMBRA, Rodrigo; ARAÚJO, Francisco Rossal de. A natureza jurídica do Direito do Trabalho. Revista Justiça do Trabalho. Porto Alegre: HS editora, ano 26, n. 308, p. 76-100, ago. 2009; e COIMBRA, Rodrigo; ARAÚJO, Francisco Rossal de. Direito do Trabalho - I. São Paulo: LTr, 2014. 
Não obstante, as normas protecionistas procuram conduzir a relação laboral para um patamar de equilíbrio, visando a minorar a desigualdade econômica entre as partes. A relação jurídica fundamental, entretanto, permanece de Direito Privado. Nesse sentido, predomina atualmente na doutrina trabalhista pátria o entendimento de que o Direito do Trabalho tem origem no Direito Privado. (DELGADO, 2009; NASCIMENTO, 2004; MARTINS, 2005)

Coimbra e Araújo (2014) ressalvam que a situação se modifica quando se analisa a natureza jurídica do direito coletivo do trabalho, pois nessa subdivisão do Direito do Trabalho o ordenamento permite que as próprias partes destinatárias constituam normas para empresas ou categorias (acordo coletivo e convenção coletiva de trabalho), ou por meio de decisões judiciais em dissídios coletivos (sentença normativa). Nesse sentido, entende-se que no âmbito coletivo o Direito do Trabalho tem natureza jurídica de Direito Público, pois aqui o poder legislativo delega ao Tribunal formar normas de caráter cogente (poder normativo da Justiça do Trabalho). Não se trata de um Direito Público tradicional, pois o órgão que emite a norma não é um órgão estatal tradicional. Em regra, as normas de caráter genérico e abstrato, com natureza cogente, emergem do Poder Legislativo ou do Poder Executivo quando este tiver uma função legislativa delegada (medidas provisórias, por exemplo).

No caso do Direito Coletivo do Trabalho, a função legislativa delegada é endereçada aos entes sindicais, que tem natureza de pessoa jurídica de direito privado. Por essa razão, trata-se de uma função legislativa anômala, delegada a entes privados, mas com extensão coercitiva para pessoas distintas daquelas que participaram da pactuação. Esse é o grande diferencial do Direito do Trabalho: a possibilidade de gerar normas de validade e eficácia erga omnes especial em relação aos integrantes das categorias envolvidas na negociação coletiva e/ou na ação de dissídio coletivo. Essa natureza mais se aproxima da atividade legislativa (natureza pública) do que da atividade negocial-contratual (natureza privada). (COIMBRA, 2014)

No que tange á constitucionalização do Direito Privado, os artigos $7^{\circ}$ ("São direitos dos trabalhadores (...): (...) XV - repouso semanal remunerado, preferencialmente aos domingos”) e 114 (que trata da competência da Justiça do Trabalho, tanto em sua redação original quanto após, modificada em 2014 pela Emenda Constitucional no 45) são exemplos no âmbito dos direitos sociais dos trabalhadores, insculpidos na Constituição Federal de 1988. (BRASIL, 2015a)

Simbolicamente, a partir de 1988, iniciou-se o processo de unificação do ordenamento jurídico pátrio, pois a atual Constituição Federal passou a definir os princípios básicos da vida social, as regras da ordem jurídica comuns aos vários ramos do Direito. (COIMBRA, 2014) 
Nessa trilha, a constitucionalização do Direito Privado não significou apenas o deslocamento geográfico do seu centro, tratou-se de um processo que importou em modificações substantivas relevantes na forma de se conceber e encarar os principais conceitos e instituições sobre os quais se funda este ramo do saber jurídico. (SARMENTO, 2006, p. 83)

Assim, mesmo a Constituição consagrando direitos sociais e econômicos e apontando novos rumos à sociedade não era vista como autoaplicável, surgindo assim, a teoria das normas constitucionais autoaplicáveis e as não autoaplicáveis, o que fazia com que a Carta Maior dependesse de normas infraconstitucionais para ter eficácia.

Foi a partir da obra de Vezio Crisafulli (La Constituzione e le sue Disposizioni di Principio - 1952), constitucionalista italiano, que passa-se a reconhecer que toda norma constitucional tem uma eficácia ainda que mínima. Após, Konrad Hesse lançou sua teoria sobre a "força normativa da Constituição", em 1992, que sustentou que a Constituição teria uma pretensão de eficácia, pois aspiraria a ordenar o fato social e a influir sobre ele, não se contentando em ser um mero espelho das relações de poder. (SARMENTO, 2006, p. 49-55)

Com o reconhecimento da força normativa da Constituição e do caráter vinculante dos seus princípios, desencadeou-se o processo de constitucionalização do Direito Privado, relativizando a dicotomia público/privado, bem como retirando o Código Civil do centro do sistema do Direito Privado, fazendo com que a ordem jurídico-privada passasse a girar em torno da pessoa humana e de seus valores existenciais. (SARMENTO, 2006)

Nessa linha, a Constituição estabeleceu direitos sociais e econômicos e apontou caminhos, metas e objetivos a serem perseguidos pelos Poderes Públicos e pelos particulares a fim de transformar a sociedade, fecundando o Direito Privado com ideais igualitários e solidarísticos, impondo uma releitura sob a ótica de conceitos e institutos tradicionais chamado por alguns juristas de neoconstitucionalismo. (SARMENTO, 2006)

O marco histórico do novo constitucionalismo no Brasil foi a redemocratização. O marco filosófico foi o pós-positivismo, pois, para ele, a doutrina pós-positivista se inspirou na revalorização da razão prática, na teoria da justiça e na legitimação democrática. Nesse contexto, busca o novo constitucionalismo ir além da legalidade estrita, mas não despreza o direito posto; procura empreender uma leitura moral da Constituição e das leis, mas sem recorrer a categorias metafísicas. (BARROSO, 2009)

Diversamente, entende Streck (2014) que o pós-positivismo e o neoconstuticionalismo não superaram o positivismo, não possuindo as características defendidas por Barroso, pois se mantêm atrelados nas ideias de junção de direito e moral, na mistura de matrizes teóricas incompatíveis, na discricionariedade e protagonismo judiciais. Streck discorre a respeito do vol.09, n. 03, Rio de Janeiro, 2016. pp. 
constitucionalismo contemporâneo, pois sendo a força normativa da Constituição uma das principais características desse novo Constitucionalismo, ela constrói uma gama de obrigações e busca a concretização dos direitos constitucionais de toda ordem.

Esse Constitucionalismo Contemporâneo se caracteriza por ser um movimento que surge como superação ao positivismo jurídico, numa perspectiva de descontinuidade, implicando um novo olhar sobre o fenômeno jurídico, através do estabelecimento de novas teorias: das fontes, da norma e da interpretação. A primeira está ligada à onipresença da Constituição, acabando com o fetichismo à independência dos sistemas. A segunda estabelece que os princípios constitucionais servem como proteção contra arbitrariedades, em busca da coerência e integridade do direito. Quanto à teoria da interpretação, a Constituição passa a ser o parâmetro para as respostas corretas, ou seja, as decisões judiciais devem estar de acordo com os princípios constitucionais, a fim de que o jurisdicionado e a coletividade tenham seus direitos e garantias salvaguardados. (STRECK, 2014)

Desta forma, a partir do momento em que a Constituição passou a guiar os demais sistemas do Direito, através de sua força normativa, de seus princípios e do estabelecimento de direitos sociais, esperou-se muito mais do Estado e do Direito, no sentido de que possam responder aos anseios da sociedade, impedindo os conflitos, ou, transformando-os em respostas positivas ao corpo social, através da normatização de comportamentos.

Isto se percebeu em grande monta no Direito do Trabalho, haja vista que, muito embora a maioria das normas tenham sido dispostas na Consolidação das leis do trabalho, que é posterior à Constituição brasileira de 1988, esta trouxe em seu bojo direitos trabalhistas e, em razão da prevalência no ordenamento jurídico, passaram a ser tratados com maior importância. Tudo isso em razão dos valores de solidarísticos e de dignidade da pessoa humana que inspiram a Constituição e perpassam o ordenamento jurídico brasileiro.

\section{A evolução do direito do trabalho: do nascedouro à constitucionalização}

O surgimento do Direito do Trabalho está intrinsecamente relacionado ao advento da Revolução Industrial, cuja primeira fase é um fenômeno localizado na Inglaterra, a partir da segunda metade do século XVIII até o início do século XIX, marco de um conjunto de transformações decorrentes da descoberta do vapor como fonte de energia e da sua aplicação nas fábricas e meios de transportes. Esse conjunto de fatores econômicos, atuando de forma interligada, provocou uma revolução sem precedentes na história da humanidade. (OLEA, 1984, p. 159)

A Revolução Industrial determinou uma mudança "generalizada e intensa, e, neste vol.09, nº. 03, Rio de Janeiro, 2016. pp.

1655 
sentido, foi uma verdadeira revolução, e uma agitação profunda, não só industrial, mas também social e intelectual, embora seus impactos não fossem instantâneos", pois foram prolongados pelo tempo, vindo a produzir frutos nas mais diversas áreas sociais. (COIMBRA; ARAÚJO, 2014, p. 20)

Até este momento histórico, o resultado do trabalho ficava com quem o produzia (trabalho livre). A partir de então, o resultado do trabalho não fica mais com o trabalhador, que passa a trabalhar para outrem (trabalho subordinado). Isso é um divisor de águas na história da humanidade. (SUSSEKIND, 2002, p. 41)

A partir da metade do século XIX ao início do século XX, o fenômeno da Revolução Industrial se expandiu, chegando à Europa (França, Holanda, Bélgica, Alemanha, Itália (norte) e Espanha (Catalunha e País Basco)) e América do Norte (norte dos EUA e Canadá), chegando ao Japão, em razão do desenvolvimento da indústria química, elétrica, petrolífera e do aço. A livre concorrência cedeu espaço ao monopólio. O taylorismo e o fordismo dominaram a nova dinâmica da produção industrial, através das linhas de montagem e da redução de estoques, com a maquinização do trabalho, o que levou os trabalhadores a reagirem e formarem sindicatos para, organizados, procurarem soluções para a situação cada vez mais desfavorável nas indústrias. Ademais, as greves passaram a ser frequentes, além de embates violentos entre trabalhadores e força policial, já que as condições de trabalho eram péssimas, mulheres e crianças trabalhavam extensas jornadas sem qualquer diferenciação protetiva, não havia salário mínimo, intervalos, repouso semanal, as jornadas eram de 18, 20h diárias, pois não havia qualquer intervenção estatal nas relações entre trabalhador e empregador. (COIMBRA; ARAÚJO, 2009)

Em 1848, Marx e Engels publicaram o "Manifesto do Partido Comunista" externando ao mundo os protestos dos trabalhadores em relação às lutas sociais, paradas de trabalho, prisões, mortes e todo o tipo de desordens em voga na época. Essa obra histórica contêm inúmeras reivindicações dos trabalhadores da época, que hoje parecem simples, como a limitação da jornada de trabalho, o salário mínimo, as férias, seguro contra acidentes, entre outros. (GOMES; GOTTSCHALK, 2007)

Somando-se as reivindicações de intelectuais como Marx e Engels, teve papel marcante no surgimento do Direito do Trabalho, o posicionamento da Igreja Católica, por meio dos seus documentos denominados Encíclicas. Para o surgimento do Direito do Trabalho a encíclica de maior significado e repercussão foi a Rerum Novarum (Coisas Novas), do Papa Leão XIII, datada de 15 de maio de 1891, pela qual a igreja reconhecia a injustiça social da época, acabando por aceitar e recomendar a intervenção estatal na economia como único meio capaz vol.09, n. 03, Rio de Janeiro, 2016. pp. 
de cobrar os abusos do regime. Exigiu toda uma legislação protetora. (NASCIMENTO, 1998, p. 44)

Zola (2006, p. 42, 61, 127-128 e 146), em sua aclamada obra "O Germinal”, captou com riqueza de detalhes o sofrimento do operariado europeu, humilhado pela exploração do capital:

[...] O operário não podia aguentar mais; a revolução só servira para agravarlhes as misérias; a partir de 89 os burgueses é que se enchiam, e tão vorazmente que nem deixavam um resto no fundo do prato para o trabalhador lamber. Quem poderia demonstrar que os trabalhadores tinham tido um quinhão razoável no extraordinário aumento da riqueza e bem-estar dos últimos cem anos? Zombaram deles ao declará-los livres. Livres para morrerem de fome, isso sim, e do que, aliás, não se privavam. Não dava pão a ninguém votar em malandros que, eleitos, só queriam locupletar-se pensando tanto nos miseráveis como nas suas botas velhas. Era preciso terminar com isso, de uma maneira ou de outra: ou por bem, por meio de leis, num acordo amigável, ou por mal, como selvagens, queimando tudo e devorando-se uns aos outros. [...] Não, não, a vida não tinha graça alguma.

Avançando para após a Primeira Guerra Mundial (1914-1918), o Direito do Trabalho ganhou visibilidade com a assinatura do Tratado de Versalhes, em 1919, em Paris, pois neste se firmou o entendimento de que o trabalho humano não poderia ser tratado como mercadoria (artigo $4^{\circ}$ ), assim como estabeleceu direitos trabalhistas tais como jornada de 8 horas, igualdade de salário para trabalho de igual valor, repouso semanal, inspeção do trabalho, salário mínimo, proteção especial ao trabalho das mulheres e dos menores, dispondo também sobre direito sindical (art. 427). (HEPLE, 1994, p. 339)

O Tratado de Versalhes confere posição definitiva aos ordenamentos jurídicos nacionais e internacionais (sobretudo pela ação da Organização Internacional do Trabalho OIT, também criada em 1919, que desenvolveu um importante papel de universalização do Direito do Trabalho). (BARROS, 2008, p. 62)

A ideia mais importante expressa tanto pelo Tratado de Versalhes como pela Constituição da Organização Internacional do Trabalho, é a de que a intranquilidade social é resultante da inexistência ou dos defeitos da regulamentação do trabalho de cada país, e gera tensões que ameaçam a paz e a tranquilidades gerais. Partindo dessa noção e tomando por base as condições existentes em países industrialmente mais adiantados, passou-se a buscar, por meio de convênios e recomendações, impor a cada país a obrigação de promulgar normas de Direito Interno, que elevem efetivamente as condições de trabalho. (COIMBRA; ARAÚJO, 2014)

O dimensionamento jurídico das relações normativas entre trabalhadores e patrões, na sua forma atual, se dá pela influência das relações coletivas, que vão gerar as normas básicas de negociação coletiva e as normas individuais de redução de jornada, repousos remunerados, 
férias, entre outros. Não haveria princípio protetivo, ou mesmo um mínimo de intervenção do Estado na regulamentação dos conflitos entre capital e trabalho, se não houvesse o movimento coletivo. (COIMBRA; ARAÚJO, 2014)

Em resumo, o Direito do Trabalho não nasce como um apêndice do Direito Civil, ou como especificação de um determinado contrato (locação de serviços). Sua principal característica e fator de diferenciação vêm dos conflitos coletivos e, por consequência, do Direito Coletivo. O contrato de locação de serviços era conhecido e serviu como veículo para a normatização das relações de trabalho nos primeiros momentos da Revolução Industrial. Entretanto, foi o movimento de reivindicação de trabalhadores, organizado no movimento sindical que mudou a concepção jurídica do contrato de locação de serviços e fez surgir o que hoje se conhece por contrato de trabalho. (COIMBRA; ARAÚJO, 2014)

Portanto, as normas jurídicas que regulam as relações individuais do trabalho são uma consequência do desenvolvimento do Direito Coletivo do trabalho. Com isso, surge nos trabalhadores a noção de cidadania, que se repercute na ideia de que também os trabalhadores são titulares de direitos subjetivos, e não apenas os burgueses e proprietários, como se pensava no início da Revolução Francesa. (COIMBRA; ARAÚJO, 2014)

Nessa linha, inicia-se no âmbito dos ordenamentos jurídicos nacionais um movimento de elevação dos princípios e normas de Direito do Trabalho ao plano constitucional, que se dá o nome de "constitucionalismo" ou "constitucionalização" social e ocorre por meio da inclusão de leis trabalhistas nas constituições nacionais. A primeira Constituição do mundo a dispor sobre Direito do Trabalho, ou normas de direitos sociais, foi a Constituição do México de 1917. Todavia, em termos de repercussão mais ampla, foi a Constituição de Weimar (Alemanha - 1919) o paradigma de inclusão dos direitos sociais nas cartas constitucionais. (COIMBRA; ARAÚJO, 2009)

No Brasil, o Direito do Trabalho, propriamente dito, começou a surgir, efetivamente, após a Revolução de 1930. Antes disso, mesmo no tempo do império, tivemos leis sociais sobre o trabalho, porém não era ainda "legislação social", mas apenas disposições legislativas fragmentárias ${ }^{5}$. (CESARINO JUNIOR; CARDONE, 1993, p. 77)

A era Getúlio Vargas não inaugura a legislação social no País, eis que conforme acima referido, na República Velha, foram editadas algumas normas esparsas de proteção ao trabalho,

\footnotetext{
${ }^{5}$ Cesarino Junior e Cardone denominam o período de 1500 a 1888 como "pré-histórico", por nada haver a referir quanto ao Direito do Trabalho, devido ao trabalho escravo (CESARINO JUNIOR, Antônio Ferreira; CARDONE, Marly A. Direito social. São Paulo: LTr, 1993, p. 77). Nesse sentido, segundo Evaristo de Moraes Filho, a chamada Lei Áurea de 1888 "significou, por si só, a primeira grande lei social entre nós, acabando com a escravidão e instituindo o regime do trabalho livre" (MORAES, Evaristo de. Apontamentos de direito operário. 4.ed. São Paulo: LTr, 1998, p. 32 do prefácio escrito por Evaristo de Moraes Filho).
} vol.09, $\mathrm{n}^{\circ}$. 03, Rio de Janeiro, 2016. pp. 
mas é a partir do momento em Vargas assume o poder em 1930, que o Direito do Trabalho passa a ser estruturado no Brasil. (COIMBRA; ARAÚJO, 2014)

Da Constituição de 1934, pioneira em direitos trabalhistas no país, somada à sistematização e à expansão de direitos infraconstitucionais por meio da Consolidação das Leis do Trabalho de 1943, segue-se um caminho de avanços e retrocessos até se chegar à atual Constituição de 1988, prevendo, entre os direitos e garantias fundamentais, direitos sociais trabalhistas (individuais e coletivos) amplos.

A constitucionalização do Direito do Trabalho, também chamada de Direito Constitucional do Trabalho ${ }^{6}$ ou Constitucionalismo Social, se caracteriza por ser um "conjunto de normas e princípios constitucionais concernentes à proteção dos direitos dos trabalhadores". Esse movimento de constitucionalização do Direito do Trabalho consagra os princípios e valores do ordenamento jurídico, em especial o da dignidade da pessoa humana, pois se preocupa com a valorização da pessoa do trabalhador, o qual deve ser protegido contra arbitrariedades do Estado e do empregador, de condições prejudiciais à sua saúde e bem-estar, ao trabalho desumano, degradante e cruel, etc.. (SILVA, 1977, s/p)

Os direitos sociais dos direitos dos trabalhadores, de acordo com Sarlet (2011), são direitos fundamentais constitucionalmente assegurados e direitos humanos pelo seu forte vínculo (pelo menos em boa parte dos casos) com a dignidade da pessoa humana ${ }^{7}$ e o correlato direito (e garantia) a um mínimo existencial, possuindo titularidade individual e coletiva (assim como difusa) em relação de coexistência e complementariedade.

Para que o Direito do trabalho permaneça na sua função de elevação da dignidade dos trabalhadores, é preciso um consenso mínimo sobre sua importância na esfera pública, e não exclusivamente privada. Relações de trabalho com dignidade são também um interesse do Estado, para diminuir tensões sociais e diminuir o peso das prestações previdenciárias. (COIMBRA; ARAÚJO, 2014)

Embora exista, formalmente, a estipulação constitucional dos direitos trabalhistas na qualidade de direitos e garantias fundamentais, o que se percebe é que na sociedade globalizada e multicultural, a situação de muitos trabalhadores ainda é "desumana", no sentido de coisificação, de atomização do ser humano trabalhador, destituindo-o da condição de

\footnotetext{
${ }^{6}$ Expressão usada, por exemplo, por: STURMER, Gilberto. Direito Constitucional do Trabalho no Brasil. São Paulo: Atlas, 2014; SILVA, Floriano Correa Vaz da. Direito constitucional do trabalho. São Paulo: Ltr, 1977.

${ }^{7}$ Conforme ALVARENGA, Rúbia Zanotelli de. O direito do trabalho como dimensão dos direitos humanos. São Paulo: Ltr, 2009, p. 43 e 172; PADILHA, Norma Sueli. Meio ambiente do trabalho equilibrado: um direito fundamental do trabalhador. In: Diálogos entre o Direito Trabalho e o Direito Constitucional: estudos em homenagem a Rosa Maria Weber. SARLET, Ingo Wolfgang; MELO FILHO, Luiz Philippe Vieira de; 
sujeito. (MORAES, 2009, p. 85)

Desta forma, segundo Engelmann (2005), é necessário “[...] pensar o sujeito como pessoa - e não como um ente abstrato e desconectado da vida. É necessário respeitar o ser humano como um sujeito desejante e pensante".

Assim, o Direito do Trabalho origina-se dos conflitos coletivos de trabalho, fermentados pelas lutas sociais ao longo da Revolução Industrial e dos séculos que se seguiram, do engajamento de intelectuais como Marx e Engels e da Igreja Católica, dos efeitos pré e pós Guerras Mundiais, dos períodos de governos contrários à democracia, da criação da Organização Internacional do Trabalho, dentre outros aspectos. E, segue se modificando, com o passar dos tempos, conforme os anseios sociais, a realidade econômica e as novas tecnologias.

A evolução do Direito Constitucional e o surgimento e desenvolvimento do Direito do Trabalho (e sua constitucionalização) demonstram a força que a dignidade humana representa para que o indivíduo se perceba em sua identidade e como detentor de direitos, na linha do que será abordado em seguida.

\section{O DIREITO DO TRABALHO NO BRASIL PÓS CONSTITUIÇÃO DE 1988: UM OLHAR DAS RELAÇÕES TRABALHISTAS A PARTIR DA DIGNIDADE HUMANA E DA CONSTITUCIONALIZAÇÃO DO DIREITO DO TRABALHO}

Após a Constituição brasileira de 1988, o princípio da dignidade da pessoa humana, consagrado como fundamento da República Federativa do Brasil, passou a ser tratado como o “epicentro axiológico da ordem constitucional, irradiando efeitos sobre todo o ordenamento jurídico e balizando não apenas os atos estatais, mas também toda a miríade de relações privadas". (SARMENTO, 2006, p. 86)

A partir de tal reconhecimento do princípio da dignidade da pessoa humana a “despatrimonialização do Direito Privado", pretendeu redefinir a ordem pública, da qual não se podem excluir as relações jurídicas privadas, de modo que a tutela da pessoa humana é elevada "ao ápice do ordenamento", "funcionalizando a atividade econômica privada aos valores existenciais e sociais" definidos na Constituição. A despatrimonialização implicou no "reconhecimento de que os bens e direitos patrimoniais não constituem fins em si mesmos, devendo ser tratados pela ordem jurídica como meios para a realização da pessoa humana". 
(SARMENTO, 2006, p. 90-91)

Segundo Barroso (2009), o princípio da dignidade humana identifica um espaço de integridade a ser assegurado a todas as pessoas por sua só existência no mundo. É um respeito à criação, independente da crença que se professe quanto à sua origem. A dignidade relacionase tanto com a liberdade e valores de espírito quanto com as condições materiais de subsistência. O desrespeito a esse princípio terá sido um dos estigmas dos séculos precedentes e a luta por sua afirmação, um símbolo do novo tempo. Ele representa a superação da intolerância, da discriminação, da exclusão social, da violência, da incapacidade de aceitar o outro, o diferente, na plenitude de sua liberdade de ser, pensar e criar.

Sobre o conceito de dignidade humana, Kaufmann (2013) aduz que consiste num conceito normativo que deve proteger todo homem de ser tratado por outro como meio, isto é, como simples objeto para a consecução de seus fins, isso implica que todos sejam tratados como possuidores de um certo grau de dignidade contingente, o que é uma tentativa de proteger o ser humano de humilhações.

Assim, o referencial mais consistente do conceito de dignidade humana é dado pelos processos de emancipação e de combate à discriminação, nos quais, além da reivindicação de proteção, reivindica-se que o homem seja reconhecido em sua dignidade com independência de seu posto social, credo, cor e sexo. (KAUFMANN, 2013, p. 55)

Esclarece $\mathrm{Kant}^{8}$ os fundamentos de sua tese sobre o valor da dignidade:

O que se relaciona com as inclinações e necessidades gerais do homem tem um preço venal; aquilo que, mesmo sem pressupor uma necessidade, é conforme a um certo gosto, isto é, a uma satisfação no jogo livre e sem finalidade das nossas faculdades anímicas, tem um preço de afeição ou de sentimento (Affektionspreis); aquilo porém que constitui a condição só graças à qual qualquer coisa pode ser um fim em si mesma, não tem somente um valor relativo, isto é, um preço, mas um valor íntimo, isto é, dignidade. [...] Esta apreciação dá, pois, a conhecer como dignidade o valor de uma tal disposição de espírito e põe-na infinitamente acima de todo o preço. Nunca ela poderia ser posta em cálculo ou confronto com qualquer coisa que tivesse um preço, sem de qualquer modo ferir a sua santidade. (KANT, 1980, p. 140)

O entendimento de Hegel (1986) quanto à dignidade é que o ser humano deve reconhecer o outro como digno, como detentor de direitos, para também ser reconhecido como tal. A reciprocidade é fortemente marcada nos escritos hegelianos, de modo que vale sua abordagem para as questões trabalhistas. O agir humano, para benefício próprio, através da utilização de outro ser humano como instrumento não pode ser válido do ponto de vista moral, pois, para Kant (1980), essa conduta não pode ser universalizada e, para Hegel, a responsabilidade para com as consequências dessa ação pertence ao agente e, se reconheço o

${ }^{8}$ KANT, Immanuel. Fundamentação da metafísica dos costumes. Tradução de Paulo Quintela. São Paulo: vol.09, nº. 03, Rio de Janeiro, 2016. pp. 
outro como mero meio, não posso me reconhecer como um fim em mim mesmo, como um ser detentor de dignidade.

Demonstrando as consequências da inobservância da noção de dignidade da pessoa humana Sarlet (2008, p. 61) explica que:

[...] onde não houver respeito pela vida e pela integridade física e moral do ser humano, onde as condições mínimas para uma existência digna não forem asseguradas, onde não houver limitação do poder, enfim, onde a liberdade e a autonomia, a igualdade (em direitos e dignidade) e os direitos fundamentais não forem reconhecidos e minimamente assegurados, não haverá espaço para a dignidade da pessoa humana e esta (a pessoa), por sua vez, poderá não passar de mero objeto de arbítrio e injustiças. Tudo, portanto, converge no sentido de que também para a ordem jurídicoconstitucional a concepção do homem-objeto (ou homem-instrumento), com todas as consequências que daí podem e devem ser extraídas, constitui justamente a antítese da noção de dignidade da pessoa, embora esta, à evidência, não possa ser, por sua vez, exclusivamente formulada no sentido negativo (de exclusão de atos degradantes e desumanos), já que assim se estaria a restringir demasiadamente o âmbito de proteção da dignidade.

A dignidade da pessoa humana possui função integradora e hermenêutica, porque serve de parâmetro para aplicação, interpretação e integração não apenas dos direitos fundamentais e das demais normas constitucionais, mas de todo o ordenamento jurídico. (SARLET, 2008, p. 61)

Por outro lado, Tribe e Dorf (1991) argúem no sentido de que a dignidade não deve ser tratada como um espelho no qual todos vêem o que desejam ver, pena de a própria noção de dignidade e na sua força normativa correr o risco de ser banalizada e esvaziada. Com efeito, não é à toa que, a partir da observação das hipóteses em que violações da dignidade foram esgrimidas na esfera judicial, se chegou a afirmar que quanto mais elevado o valor que tem sido atribuído à dignidade, mais triviais os objetivos para os quais tem sido invocada, assim, resulta evidente que nem mesmo em nome da dignidade se pode dizer qualquer coisa.

Sarlet (2008, p. 112 e 122) segue fundamentando que "a dignidade da pessoa humana atua como fundamento dos direitos fundamentais, sendo medida e também elemento dos mesmos", arrematando o Direito e a sociedade "exigem uma compreensão inclusiva e abrangente da dignidade da pessoa humana e dos direitos e deveres fundamentais que lhe são inerentes", se pretendem ressaltar valores de fraternidade e de solidariedade.

Relacionando o trabalho humano com a dignidade da pessoa humana Freitas Júnior (2006, p. 104) destaca:

[...] hoje, portanto, mantém-se a vida com o labor, mas ele não é apenas atividade do animal laborans; transformou-se na forma de realização do homem, que realiza o seu trabalho não somente para atender às necessidades 
de sua existência. A partir do trabalho, o homem mantém sua vida e desenvolve suas potencialidades, agindo e participando da sociedade. Trabalhar é a forma com que a maioria das pessoas no globo terrestre encontra para buscar uma vida com dignidade. É indispensável, portanto, que não apenas seja assegurado o trabalho, mas este em condições dignas.

Levando-se em consideração que o trabalho é fator de estima social, possibilita ao ser humano que se desenvolva em sua identidade e particularidade e seja reconhecido como detentor de direitos e, pelo viés da dignidade, perceba essa característica dos demais, superando-se os conflitos.

Nessa trilha, Delgado (2014, p. 208) sintetiza que o princípio da dignidade da pessoa humana "traduz o valor central das sociedades" e trata-se do "princípio maior do Direito Constitucional contemporâneo, espraiando-se, com grande intensidade, no que tange à valorização do trabalho".

Com fundamento na filosofia de Honneth, Aldacy Rachid Coutinho (2014, p. 95) afirma que "a dignidade, na sua expressão trabalho, se situa nesse âmbito de demanda de reconhecimento pelo Outro da condição de ser sujeito de direitos" e sustenta que o crescimento quantitativo e qualitativo dos discursos em torno da dignidade da pessoa humana "denota mais o seu fracasso nesse modo de produção capitalista", pois [...] "ninguém pretenderá ver reconhecido o que se tem".

Em uma sociedade plural e democrática, o papel desempenhado pelo contrato de trabalho é de fundamental importância para a efetivação da dignidade da pessoa humana.

A constitucionalização do contrato de trabalho em toda sua amplitude conceitual e de abrangência de direitos e obrigações é uma realidade importante. (NASCIMENTO, 2011) Nesse contexto, o contrato de trabalho precisa avançar rumo ao desiderato de concretização da Constituição e dos direitos fundamentais (CANOTILHO, 1991), e uma das formas que o Direito Constitucional já vem há alguns anos utilizando em casos em que as teorias comuns não resolvem certos problemas, está na maior aplicação da chamada "eficácia horizontal dos direitos fundamentais", ou seja, além de vincularem todos os poderes públicos (eficácia vertical), os direitos fundamentais exercem sua eficácia vinculante também na esfera jurídicoprivada, isto é, no âmbito das relações jurídicas entre particulares. (SARLET, 2011, p. 374)

Como no Direito do Trabalho tudo depende do modo e da fundamentação que se usa o instrumental, dúvidas que podem ser verificadas nos exemplos a seguir expostos, que não representam a opinião do presente autor quanto à adequação ou não da sua utilização, mas tão somente procuram mostrar como a temática vem sendo utilizada no âmbito doutrinário e jurisprudencial, no Direito do Trabalho.

De acordo com concepção amplamente consagrada, os direitos fundamentais vol.09, n. 03, Rio de Janeiro, 2016. pp. 
expressam uma ordem de valores objetivada na e pela Constituição (explícita ou implicitamente $)^{9}$, que é o caso do direito do trabalho no Direito Brasileiro, em que o capítulo II, da CF de 1988 elenca uma série (não exaustiva) de direitos fundamentais sociais dos trabalhadores, entre os arts. $7^{\circ}$ a 11 . Portanto, no Brasil, os direitos sociais dos trabalhadores são fundamentais ${ }^{10}$, por opção explícita da nossa Constituição Federal, ainda que se possa discutir a fundamentalidade de alguns direitos específicos, o que não é o objeto do presente trabalho, mas fica o registro, pois tal fundamentalidade não é absoluta e muito menos atemporal.

Ademais, da norma contida no parágrafo $2^{\circ}$ do art. $5^{\circ}$ da CF de 1988 (BRASIL, 2015a) ${ }^{11}$, seguindo a tradição do nosso direito constitucional republicado, desde a Constituição de fevereiro de 1891, pode-se extrair o entendimento de que, "para além do conceito formal de Constituição (e de direitos fundamentais), há um conceito material, no sentido de existirem direitos que, por seu conteúdo, por sua substância, pertencem ao corpo fundamental da Constituição de um Estado, mesmo não constando no catálogo" (SARLET, 2011, p. 76).

Esta força vinculante também tem sido denominada sob os títulos de eficácia privada, eficácia externa ou eficácia em relação a terceiros, e iniciou no âmbito da doutrina e jurisprudência alemã da segunda metade do século passado ${ }^{12}$, passando a atrair posteriormente

\footnotetext{
${ }^{9}$ Um determinado direito é fundamental "não apenas pela relevância do bem jurídico tutelada em si mesma (por mais importante que o seja), mas pela relevância daquele bem jurídico na perspectiva das opções do Constituinte, acompanhada da atribuição da hierarquia normativa correspondente e do regime jurídicoconstitucional assegurado pelo Constituinte às normas de direitos fundamentais", conforme explica Sarlet (p. 76). É por essa razão que um direito pode ser fundamental em um país e não ser em outro. Todavia, isso não significa dizer que seja possível reduzir a noção de direitos fundamentais a um conceito meramente formalista ou mesmo nominal, como sendo apenas os direitos expressamente consagrados como tais, o que leva ao tema da abertura material do catálogo de direitos fundamentais no direito constitucional positivo brasileiro (p. 77). Sobre a exigibilidade em juízo ("justicialidade”) dos direitos fundamentais a prestações positivas do Estado ver TALAMINI, Eduardo. Concretização jurisdicional de direitos fundamentais a prestações positivas do Estado. In: Instrumentos de coerção e outros temas de direito processual civil: estudos em homenagem aos 25 anos de docência do Professor Dr. Araken de Assis. Rio de Janeiro: Forense, 2007, p. 151-155.

${ }^{10}$ Para um estudo detalhado do reconhecimento dos direitos sociais dos trabalhadores como típicos direitos fundamentais ver SANTOS JUNIOR, Rubens Fernando Clamer dos. A eficácia dos direitos fundamentais dos trabalhadores. São Paulo: Ltr, 2010, p. 47-52; Existem interpretações mais extensivas. Por exemplo, Rubia Zanotelli de Alvarenga defende o direito do trabalho como dimensão dos direitos humanos, enquanto “direitos naturais, inatos, imutáveis e inderrogáveis, de inspiração jusnaturalista, que ultrapassam a esfera positiva do Ordenamento Jurídico por emanarem da própria natureza ética do homem, independentemente de reconhecimento perante o Estado". ALVARENGA, Rúbia Zanotelli de. O direito do trabalho como dimensão dos direitos humanos. São Paulo: Ltr, 2009, p. 43.

${ }^{11} \mathrm{CF}$, art. $5^{\circ}, \S 2^{\circ}$ : "Os direitos e garantias expressos nesta Constituição não excluem outros decorrentes do regime e dos princípios por ela adotados, ou dos tratados internacionais em que a República Federativa do Brasil seja parte".

12 A supremacia dos direitos fundamentais em relação ao Direito Privado é retratada com inestimável sistematização por Canaris, que traz o histórico do debate no Tribunal Constitucional Alemão, com o histórico caso "Luth", em que um cidadão de nome Luth apelou, em 1950, aos proprietários e frequentadores de salas de cinema ao boicote de um novo filme, argumentando que o diretor do mesmo rodara um file vol.09, no. 03, Rio de Janeiro, 2016. pp.

1664
} 
as atenções da doutrina europeia em geral (SARLET, 2011, 374-375), e se aplica com adequação ao contrato de trabalho, visto que pactuado por dois particulares (empregado e empregador) ${ }^{13}$.

O ponto de partida para o reconhecimento da eficácia horizontal dos direitos fundamentais está na implementação do Estado Social de Direito, no qual não apenas o Estado ampliou suas atitudes e funções, mas também a sociedade cada vez mais participa ativamente do exercício do poder (ao contrário do modelo de Estado Clássico e Liberal de Direito), de tal sorte que a liberdade individual não apenas carece de proteção contra os poderes públicos, mas também contra os mais fortes no âmbito da sociedade, isto é, os detentores de poder social e econômico, já que é nesta esfera que as liberdades se encontram particularmente ameaçadas (LEITE, 2008), o que se verifica com muita clareza nas relações de trabalho, que desde seus primórdios trabalha com essa lógica, ainda que sem essa nomenclatura, até por que no início do Direito Trabalho não se falava em direitos fundamentais, mas já se desenhava o princípio protetor e suas modalidades, como método de equilibrar juridicamente o desnível econômicosocial das partes dos contratos de trabalho.

O Direito do Trabalho também surge das reações às iniquidades do liberalismo (SUSSEKIND, 1991, p. 15). ${ }^{14}$ O principal problema decorrente dessa realidade é a desigualdade econômica entre os componentes da relação de trabalho. Empregado e empregador estão em patamares socioeconômicos diversos, pois possuem poderes desiguais e capacidades de resistência econômica distintas, o que leva a formas de exploração e aproveitamento. (PLÁ RODRIGUES, 1978, p. 28-29)

O Estado (Social) em proposital intervenção nas relações de trabalho, por meio do Poder Legislativo, compensa juridicamente, a desigualdade social existente entre as partes. Trata-se de um princípio de justiça distributiva, na concepção aristotélica de "tratar

antissemita durante o período nacional-socialista. Os tribunais cíveis consideraram o apelo um ato ilícito, por ofensivo aos bons costumes, condenando o Sr. Luth a não repeti-lo. Baseando-se sobre tudo nas clausulas gerais de direito privado em virtude da sua referência aos "bons costumes" o Tribunal Constitucional Alemão utilizou-se, pela primeira vez, da formulação entrementes célebre, de que a Lei Fundamental erigiu na seção referente aos direitos fundamentais uma ordem objetiva de valores, que deve valer enquanto decisão fundamental para todas as áreas do Direito (CANARIS, Claus-Wilhelm. A influência dos direitos fundamentais sobre o direito privado na Alemanha. In: Constituição, Direitos Fundamentais e Direito Privado. Ingo Wolfgang Sarlet (Org.). Porto Alegre: Livraria do Advogado, 2003, p. 227-228).

${ }^{13}$ Conforme o autor, "a relação empregatícia é um dos sítios naturais de sua aplicabilidade em nosso sistema jurídico".

${ }^{14} \mathrm{O}$ autor retrata as penosas condições dos trabalhadores no século XIX, informando a existência de jornadas de trabalho de 14 a 15 horas por dia, trabalho de mulheres e menores em condições deploráveis, etc. CATHARINO, José Martins. Compêndio de direito do trabalho. 3.ed. São Paulo: Saraiva, V. 1, 1982, p. 4, afirma que a história do Direito do Trabalho pode ser considerada como um capítulo da história da liberdade humana. Sobre esse assunto ver: ARIES, Philippe; DUBY, Georges (orgs). História da vida privada. São Paulo: Schwarz, 1992, Vol. 5, p. 21-154; IGELMO, Alberto José Carro. História Social del Trabajo. 7. ed. 
desigualmente os desiguais". ${ }^{15}$

O essencial no princípio protetor é a verdadeira dimensão do trabalho humano, descaracterizando-o como mercadoria e emprestando-lhe conteúdo mais amplo, no sentido de compreendê-lo como elemento valioso na dignidade da pessoa humana, daí sua íntima ligação com o direito fundamental da dignidade da pessoa humana (art. $1^{\circ}$, III, da Constituição Federal de 1988), "significativo vetor interpretativo, verdadeiro valor-fonte que conforma e inspira todo o ordenamento constitucional vigente", na expressão do Supremo Tribunal Federal. (HC 85.237-8-DF, 2005) $)^{16}$

\section{CONSIDERAÇÕES FINAIS}

A partir da constitucionalização do Direito Privado, os direitos passaram a ser norteados pelos valores e princípios da Constituição Federal. Os institutos do Direito Privado foram se modificando e, sorvidos nos valores solidarísticos da Constituição, passaram a se difundir, se especializar e gerar novos direitos.

Depois da década de 1930, no Brasil, e no início do século XX, na Europa, o "fetichismo" do Código Civil cedeu espaço aos reclames da sociedade, pelos direitos sociais, dentre os quais se destaca o Direito do(ao) Trabalho, vindo o Direito a necessitar de novas fontes, para poder garanti-los e assegura-los.

O desgaste do Código Civil aparecia, especialmente, em razão do fato de que a sociedade industrial ou pós-industrial reclamava por um direito social, ou seja, repelia o individualismo marcado no Direito Civil codificado e pelo Estado Liberal. Foi neste momento histórico que a descodificação iniciou e, pouco a pouco, determinou uma mudança radical no Direito, vindo o Código Civil a ceder espaço para sistemas jurídicos diversos, no intuito de salvaguardar respostas para problemas sociais antes não alcançados pelo direito privado, nos quais se encaixam os direitos trabalhistas.

Como consequência da descodificação, institutos anteriormente de alçada do Código

Barcelona: Bosch, 1986.

15 Sobre a noção de justiça em Aristóteles, ver AZEVEDO, Plauto Faraco de. Justiça Distributiva e Aplicação do Direito. Porto Alegre: Sérgio Fabris, 1983 e BODENHEIMER, Edgar. Teoría del Derecho. México: Fondo de Cultura Económica, 1986, p. 61-63. O fundamental da noção de justiça distributiva é a mutabilidade e adequação do tratamento considerando a situação real das partes envolvidas no conflito. No Direito do Trabalho, os juízos de valor também são adaptados levando-se em consideração as condições reais das partes. Assim, um grande empregador deve ser tratado de forma diferenciada em contraposição a uma pequena empresa de fundo de quintal. O nível de exigência de deveres de um empregado ocupante de um alto posto dentro de uma organização empresarial é diferente daquele relativo a um empregado que executa funções menos especializadas ou até mesmo braçais.

${ }^{16}$ Brasil, Supremo Tribunal Federal, HC 85.237-8-DF, Tribunal Pleno, Rel. Ministro Celso de Mello, 17.3.2005. 
Civil se tornaram parte do processo de constitucionalização do Direito Privado, passando a fazer parte do texto da Constituição, através de normas programáticas, ou mesmo de eficácia imediata, especialmente os direitos fundamentais e os direitos sociais.

Foi neste momento que iniciou o processo de unificação do ordenamento jurídico, pois a Constituição passou a definir os princípios básicos da vida social, as regras da ordem jurídica comuns aos vários ramos do Direito. Nessa trilha, a constitucionalização do Direito Privado não significou apenas o deslocamento geográfico do seu centro, tratou-se de um processo que importou em modificações substantivas relevantes na forma de se conceber e encarar os principais conceitos e instituições sobre os quais se funda este ramo do saber jurídico.

Quando os direitos dos trabalhadores, contidos na Constituição, passaram a ser respeitados sobretudo em função do que se chamou de "força normativa da Constituição", o Direito do Trabalho deu um salto evolutivo e hoje regula uma ampla gama de relações intersubjetivas, dispõe a respeito de profissões específicas, possui processo próprio, diverso e independente do Processo Civil, Justiça especializada, Tribunais, órgãos locais, regionais, nacionais e internacionais de defesa dos direitos dos Trabalhadores e Ministério Público do Trabalho (dentre outras particularidades).

O Direito do Trabalho originou-se dos conflitos coletivos de trabalho, fermentados pelas lutas sociais ao longo da Revolução Industrial e dos séculos que se seguiram, do engajamento de intelectuais como Marx e Engels e da Igreja Católica, dos efeitos pré e pós Guerras Mundiais, dos períodos de governos contrários à democracia, da criação da Organização Internacional do Trabalho, dentre outros aspectos. E, segue se modificando, com o passar dos tempos, conforme os anseios sociais, a realidade econômica e as novas tecnologias.

O movimento de constitucionalização do Direito do Trabalho consagra os princípios e valores do ordenamento jurídico, em especial o da dignidade da pessoa humana, pois se preocupa com a valorização da pessoa do trabalhador, o qual deve ser protegido contra arbitrariedades do Estado e do empregador, de condições prejudiciais à sua saúde e segurança, entre os aspectos.

Os direitos sociais dos direitos dos trabalhadores no Brasil são direitos fundamentais e humanos pelo seu forte vínculo (pelo menos em boa parte dos casos) com a dignidade da pessoa humana e o correlato direito (e garantia) a um mínimo existencial, possuindo titularidade individual e coletiva (assim como difusa) em relação de coexistência e complementariedade.

Para que o Direito do trabalho permaneça na sua função de elevação da dignidade dos vol.09, n. 03, Rio de Janeiro, 2016. pp. 
trabalhadores, é preciso um consenso mínimo sobre sua importância na esfera pública, e não exclusivamente privada. Relações de trabalho com dignidade são também um interesse do Estado, para diminuir tensões sociais e diminuir o peso das prestações previdenciárias.

Corolário dos valores da Constituição, a dignidade da pessoa humana, que é um dos esteios do Estado brasileiro, permeia o Direito e está presente no Direito do Trabalho também quando se trata a respeito das relações intersubjetivas, e não somente de salário e condições de trabalho.

Com isso, o Direito do Trabalho ainda não tem possibilitado de modo efetivo e amplo a superação de conflitos intersubjetivos decorrentes do não reconhecimento de dignidade do trabalhador, como ser humano detentor de direitos.

Embora exista, formalmente, a estipulação constitucional dos direitos trabalhistas na qualidade de direitos e garantias fundamentais, o que se percebe é que na sociedade globalizada e multicultural, a situação de muitos trabalhadores ainda está longe de seguir o vetor constitucional da dignidade da pessoa humana.

Em uma sociedade plural e democrática, o papel desempenhado pelo contrato de trabalho é de fundamental importância para a efetivação da dignidade da pessoa humana. A constitucionalização do contrato de trabalho em toda sua amplitude conceitual e de abrangência de direitos e obrigações é uma realidade importante.

O contrato de trabalho precisa avançar rumo ao desiderato de efetiva concretização da Constituição e dos direitos fundamentais, e uma das formas que o Direito Constitucional já vem utilizando em casos em que as teorias comuns não resolvem certos problemas, está na maior aplicação da chamada "eficácia horizontal dos direitos fundamentais", ou seja, além de vincularem todos os poderes públicos (eficácia vertical), os direitos fundamentais exercem sua eficácia vinculante também na esfera jurídico-privada, isto é, no âmbito das relações jurídicas entre particulares.

\title{
THE CONSTITUTIONALIZATION OF LABOR LAW ON THE TRAIL OF THE PRINCIPLE OF HUMAN DIGNITY
}

\begin{abstract}
This article deals with the constitutionalization of Labor Law in Brazil, in order to understand the reasons and the paths followed by this branch of law, starting from the Civil Law Code, through the origins of the Labor Law to its constitutionalisation, as well as challenges that this track generates for advances in labor relations. So has the constitutionalising movement of Labor Law enshrines the principles and values of the legal system, especially the dignity of the
\end{abstract}


human person, as worries about the appreciation of the worker, who should be protected from arbitrariness the state and the employer of conditions harmful to their health and safety, among other things still present in the context of a globalized and multicultural society. For this, through the systematic method and qualitative approach, it is proposed to investigate whether the Labour Law, after its constitutionalization, has made it possible to overcome intersubjective conflicts resulting from non-worker dignity of recognition as a human being holder of social rights.

Keywords: Civil Law - codification - constitutionalising - Labor Law - dignity

\section{REFERÊNCIAS}

ALVARENGA, Rúbia Zanotelli de. O direito do trabalho como dimensão dos direitos humanos. São Paulo: Ltr, 2009.

AMARAL, Francisco. Racionalidade e sistema no direito civil brasileiro. Separata da Revista O Direito, ano $126^{\circ}, 1994$, v. I-II. p. 63-81.

ARIES, Philippe; DUBY, Georges (orgs). História da vida privada. São Paulo: Schwarz, 1992, Vol. 5.

AZEVEDO, Plauto Faraco de. Justiça Distributiva e Aplicação do Direito. Porto Alegre: Sérgio Fabris, 1983.

BARROS, Alice Monteiro de. Curso de Direito do Trabalho. 4.ed. São Paulo: LTr, 2008.

BARROSO, Luis Roberto. Curso de Direito Constitucional Contemporâneo. São Paulo: Saraiva, 2009.

BRASIL. Constituição Da República Federativa do Brasil (1988). São Paulo: Saraiva, 2015.

BRASIL. Consolidação das Leis do Trabalho. São Paulo: Saraiva, 2015.

BODENHEIMER, Edgar. Teoría del Derecho. México: Fondo de Cultura Económica, 1986.

CANARIS, Claus-Wilhelm. Pensamento sistemático e conceito de sistema na ciência do direito. Tradução de António Menezes Cordeiro. 3. ed. Lisboa: Fundação Calouste Gulbenkian, 2002.

A influência dos direitos fundamentais sobre o direito privado na Alemanha. In: Constituição, Direitos Fundamentais e Direito Privado. Ingo Wolfgang Sarlet (Org.). Porto Alegre: Livraria do Advogado, 2003.

CANOTILHO, José Joaquim Gomes. Direito Constitucional. 5.ed. Coimbra: Almedina, 1991.

CATHARINO, José Martins. Compêndio de direito do trabalho. 3.ed. São Paulo: Saraiva, V. 1, 1982. 
CESARINO JUNIOR, Antônio Ferreira. CARDONE, Marly A. Direito social. São Paulo: LTr, 1993.

COIMBRA, Rodrigo. A natureza jurídica do Direito Coletivo do Trabalho.

Revista de Direito do Trabalho. São Paulo: Revista dos Tribunais, n. 155, p. 107-135, 2014. ARAÚJO, Francisco Rossal de. A natureza jurídica do Direito do Trabalho. Revista

Justiça do Trabalho. Porto Alegre: HS editora, ano 26, n. 308, p. 76-100, ago. 2009. Direito do Trabalho - evolução do modelo normativo e tendências atuais na Europa.

Revista LTr, vol. 73, no 08, p. 953-962, ago.2009. Direito do Trabalho - I. São Paulo: LTr, 2014.

COUTINHO, Aldacy Rachid. A dimensão do princípio da dignidade e a relação de trabalho. In: Diálogos entre o Direito Trabalho e o Direito Constitucional: estudos em homenagem a Rosa Maria Weber. SARLET, Ingo Wolfgang; MELO FILHO, Luiz Philippe Vieira de; FRAZÃO, Ana de Oliveira (Coords.). São Paulo: Saraiva, 2014.

DELGADO, Maurício Godinho. Curso de direito do trabalho. 8.ed. São Paulo: Ltr, 2009.

DELGADO, Gabriela Neves. O princípio da dignidade da pessoa humana e o Direito do Trabalho. In: Diálogos entre o Direito Trabalho e o Direito Constitucional: estudos em homenagem a Rosa Maria Weber. SARLET, Ingo Wolfgang; MELO FILHO, Luiz Philippe Vieira de; FRAZÃO, Ana de Oliveira (Coords.). São Paulo: Saraiva, 2014.

ENGELMANN, Wilson. A crise constitucional: a linguagem e os direitos humanos como condição de possibilidade para preservar o papel da Constituição no mundo globalizado. In: MORAIS, José Luis Bolzan de. (Org.). O Estado e suas crises. Porto Alegre: Livraria do Advogado, 2005.

FREITAS JUNIOR, Antônio Rodrigues de. Direito do trabalho e direitos humanos. São Paulo: BH Ed. e Distribuidora de Livros, 2006.

GOMES, Orlando. GOTTSCHALK, Élson. Curso de Direito do Trabalho. 18.ed. Rio de Janeiro: Forense, 2007.

HEGEL, G. W. F. Rechtsphilosophie. Frankfurt am Main: Suhrkamp, 1986.

HEPLE, Bob. La formación del Derecho del Trabajo em Europa. Madrid: Ministério de Trabajo y Seguridad Social, 1994.

IGELMO, Alberto José Carro. História Social del Trabajo. 7. ed. Barcelona: Bosch, 1986.

IRTI, Natalino. L'età della decodificazioni. 4.ed. Milano: Giuffrè, 1999.

KANT, Immanuel. Fundamentação da metafísica dos costumes e outros escritos. 1. reimp. São Paulo: Martin Claret, 2008.

KAUFMANN, Matthias. Em defesa dos direitos humanos: consideraçãoes históricas e de princípio. Tradução de Rainer Patriota. São Leopoldo: Ed. Unisinos, 2013.

LEITE, Carlos Henrique Bezerra. Eficácia horizontal dos direitos fundamentais na relação de emprego. Justiça do Trabalho. Porto Alegre: HS Editora, n. 329, p. 19, mai. 2011. 
MARTINS, Sérgio Pinto. Direito do trabalho. 21.ed. São Paulo: Atlas, 2005.

MORAES, Evaristo de. Apontamentos de direito operário. 4.ed. São Paulo: LTr, 1998.

MORAES, Maria Celina Bodin de. Danos à pessoa humana: uma leitura civil-constitucional dos danos morais. Rio de Janeiro: Renovar, 2009.

NADER, Paulo. Introdução ao Estudo do Direito. $28^{\text {a }}$ ed. Rio de Janeiro: Editora Forense, 2007.

NASCIMENTO, Amauri Mascaro. Iniciação ao Direito do Trabalho. 24.ed.. São Paulo: LTr, 1998.

Curso de direito do trabalho. 19.ed. São Paulo: Saraiva, 2004.

Direito contemporâneo do trabalho. São Paulo: Ltr, 2011.

OLEA, Manuel Alonso. Introdução aoDireito do Trabalho. 4. ed. São Paulo: LTr, 1984.

PADILHA, Norma Sueli. Meio ambiente do trabalho equilibrado: um direito fundamental do trabalhador. In: Diálogos entre o Direito Trabalho e o Direito Constitucional: estudos em homenagem a Rosa Maria Weber. SARLET, Ingo Wolfgang; MELO FILHO, Luiz Philippe Vieira de; FRAZÃO, Ana de Oliveira (Coords.). São Paulo: Saraiva, 2014.

PLÁ RODRIGUES, Américo. Princípios do Direito do Trabalho. São Paulo: LTr., 1978.

RENÉ, David. Os Grandes Sistemas do Direito Contemporâneo. Rio de Janeiro: Martins Fontes, 1998.

SANTOS JUNIOR, Rubens Fernando Clamer dos. A eficácia dos direitos fundamentais dos trabalhadores. São Paulo: Ltr, 2010.

SARLET, Ingo Wolfgang. Dignidade da Pessoa Humana e "Novos" Direitos na Constituição Federal de 1988: Algumas aproximações, 5. ed. Porto Alegre: Livraria do Advogado, 2007.

A eficácia dos direitos fundamentais: uma teoria geral dos direitos fundamentais na perspectiva constitucional. 10. ed. Porto Alegre: Livraria do Advogado, 2011.

Direitos fundamentais e processo: o direito à proteção e promoção da saúde entre tutela individual e transindividual. Revista de Processo. São Paulo, v. 199, p. 13-39, set. 2011.

SARMENTO, Daniel. Direitos fundamentais e relações privadas. 2 ed. Rio de Janeiro: Lumen Juris, 2006.

SILVA, Floriano Correa Vaz da. Direito constitucional do trabalho. São Paulo: Ltr, 1977.

SOUZA, Rodrigo Trindade. Função Social do contrato de emprego. São Paulo: Ltr, 2008.

STRECK, Lenio Luiz. Verdade e consenso - Constituição, Hermenêutica e Teorias Discursivas. 5 ed. São Paulo: Saraiva, 2014.

MORAES, José Luis Bolzan de. Ciência política e teoria do estado. 5 ed., Porto Alegre: Livraria do Advogado, 2006.

STURMER, Gilberto. Direito Constitucional do Trabalho no Brasil. São Paulo: Atlas, 2014. vol.09, n. 03, Rio de Janeiro, 2016. pp. 
SUSSEKIND, Arnaldo. et. al. Instituições de Direito do Trabalho. 11.ed. São Paulo: Ltr, 1991, V. 1.

Instituições de Direito do Trabalho. 20.ed. São Paulo: LTr, 2002, V. 1.

TALAMINI, Eduardo. Concretização jurisdicional de direitos fundamentais a prestações positivas do Estado. In: Instrumentos de coerção e outros temas de direito processual civil: estudos em homenagem aos 25 anos de docência do Professor Dr. Araken de Assis. Rio de Janeiro: Forense, 2007.

TEPEDINO, Gustavo. Premissas metodológicas para a constitucionalização do Direito Civil. In: Temas de Direito Civil. 4 ed. Rio de Janeiro: Renovar, 2008.

TIMM, Luciano Benetti. Decodificação, desconstitucionalização e reprivatização no direito privado: o Código Civil ainda é útil? The Latin American And Caribbean Journal of Legal Studies, $\quad$ v. $\quad 3, \quad 2008 . \quad 2$ Disponível em $<$ http://services.bepress.com/cgi/viewcontentcgi?article=1027\&context=lacjls $>$. Acesso em 02, $\operatorname{mar} / 2015$.

TRIBE. L. H., DORF, M. G. On reading The Constitution. Cambridge. Massachussetts: Harvard University Press, 1991.

VENOSA, Sílvio de S. Direito Civil - Parte Geral. São Paulo: Atlas, 2007.

WIEAKER, Franz. História do direito privado moderno. Tradução de A. M. Botelho Hespanha. 2.ed. Lisboa: Fundação Calouste Gulbenjian, 1967.

Trabalho enviado em 24 de janeiro de 2016.

Aceito em 23 de março de 2016. 